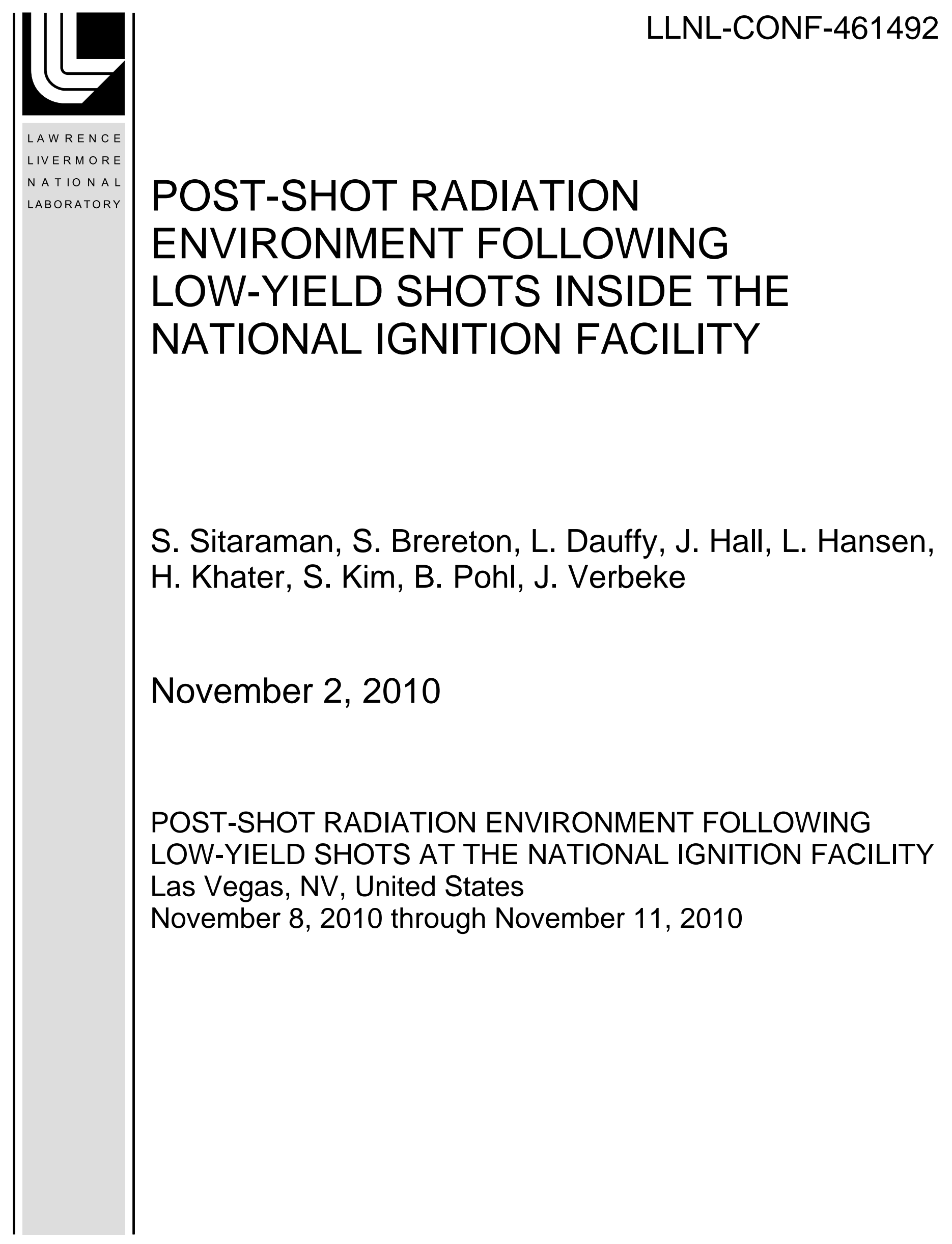


This document was prepared as an account of work sponsored by an agency of the United States government. Neither the United States government nor Lawrence Livermore National Security, LLC, nor any of their employees makes any warranty, expressed or implied, or assumes any legal liability or responsibility for the accuracy, completeness, or usefulness of any information, apparatus, product, or process disclosed, or represents that its use would not infringe privately owned rights. Reference herein to any specific commercial product, process, or service by trade name, trademark, manufacturer, or otherwise does not necessarily constitute or imply its endorsement, recommendation, or favoring by the United States government or Lawrence Livermore National Security, LLC. The views and opinions of authors expressed herein do not necessarily state or reflect those of the United States government or Lawrence Livermore National Security, LLC, and shall not be used for advertising or product endorsement purposes. 


\title{
POST-SHOT RADIATION ENVIRONMENT FOLLOWING LOW-YIELD SHOTS INSIDE THE NATIONAL IGNITION FACILITY
}

\author{
S. Sitaraman, S. Brereton, L. Dauffy, J. Hall, L. Hansen, \\ H. Khater, S. Kim, B. Pohl, J. Verbeke, and M. Young \\ Lawrence Livermore National Laboratory, Livermore, CA 94550 \\ sitaraman1@llnl.gov
}

\begin{abstract}
A detailed model of the Target Bay (TB) at the National Ignition Facility (NIF) has been developed to estimate the post-shot radiation environment inside the facility. The model includes large number of structures and diagnostic instruments present inside the TB. These structures and instruments are activated by the few nanosecond pulse of neutrons generated during a shot and the resultant gamma dose rates are estimated at various decay times following the shot. The results presented in this paper are based on a low-yield D-T shot of $10^{16}$ neutrons. General environment dose rates drop to below $3 \mathrm{mrem} / \mathrm{h}$ within three hours following a shot with higher dose rates observed at contact with some of the components. Dose rate maps of the different TB levels were generated to aid in estimating worker stay-out times following a shot before entry is permitted into the TB.
\end{abstract}

\section{INTRODUCTION}

In a facility like the National Ignition Facility (NIF), where high-energy neutron fluxes are intermittently present, it is important to analyze the radiation exposure due to the activation of surrounding materials and their subsequent decay, principally by gamma emission. A complex model of the target bay (TB) has been developed for performing radiation transport analyses to characterize the radiation environment within the TB following a shot or a series of shots. The model includes the various structural components as well as individual components like target positioners, diagnostic instruments etc. This level of complexity required the development of automation tools that perform the various steps involved in creating the dose rate maps in an efficient manner that allows for simultaneous analysis of the gamma decay of all activated structures present in the model. This study describes the model that was developed and the method of analyses followed by estimates of dose rates from a lowyield shot of $10^{16}$ neutrons.

\section{CALCULATIONAL METHODOLOGY}

The calculations were performed in three steps. The first step involved the estimation of the neutron flux spectrum in a 175-group structure for all the components in the TB that would be activated. This calculation was performed with the Monte Carlo Radiation Transport Code, $\mathrm{MCNP}^{1}$ using continuous energy data from the Fusion Evaluated Nuclear Data Library (FENDL). ${ }^{2}$ The source term for this run consisted of a 101-group D-T neutron spectrum with a yield of $10^{16}$ neutrons placed at the center of the target chamber (TC). The individual neutron spectrum was then used to activate each component in the model and produce gamma spectral data in a 25-group structure at different post-shot cooling times using the activation and decay code, ALARA. ${ }^{3}$ The gamma spectra generated were used as sources in each component and a gamma transport calculation was performed using MCNP and photoatomic data from the ENDF-VI, Release 8 data. ${ }^{4}$ The gamma fluxes were converted to effective dose rates using ICRP-74 anteriorposterior conversion coefficients. ${ }^{5}$ A rectangular mesh tally scheme with a mesh size of approximately 1'x 1' $x$ 1 ' was used to cover the entire TB model with dose rates being calculated in each mesh.

The neutron transport calculation was performed using the 'extended' MCNP TB model, where snout assemblies of the Diagnostic Instrument Manipulators (DIMs) and Target Positioners (TARPOSs) were extended into the target chamber during the shot. The gamma transport calculations were performed using the 'retracted' model, where the extended parts of these components are retracted to the outside of the TC.

Since the TB model is detailed and extremely complicated (Figures 1 and 2), an automation program, $\mathrm{AAMI}^{6}$, was developed to link the three calculational steps in a seamless manner. This program generates gamma source terms and spectra for a given post-shot cooling time, which are used by a special version of MCNP that was modified to include a user supplied 
source subroutine. The large amount of data generated in these runs for each post-shot cooling time was incorporated into a database which was accessed by a web-based tool that was developed to display effective dose rate maps inside the TB following a single shot or series of shots at any neutron yield. The tool, NIF Exposure Estimation Tool (NEET) ${ }^{7}$, will be used for work planning following shots. The database itself will be adjusted as actual dose rate measurement data become available.

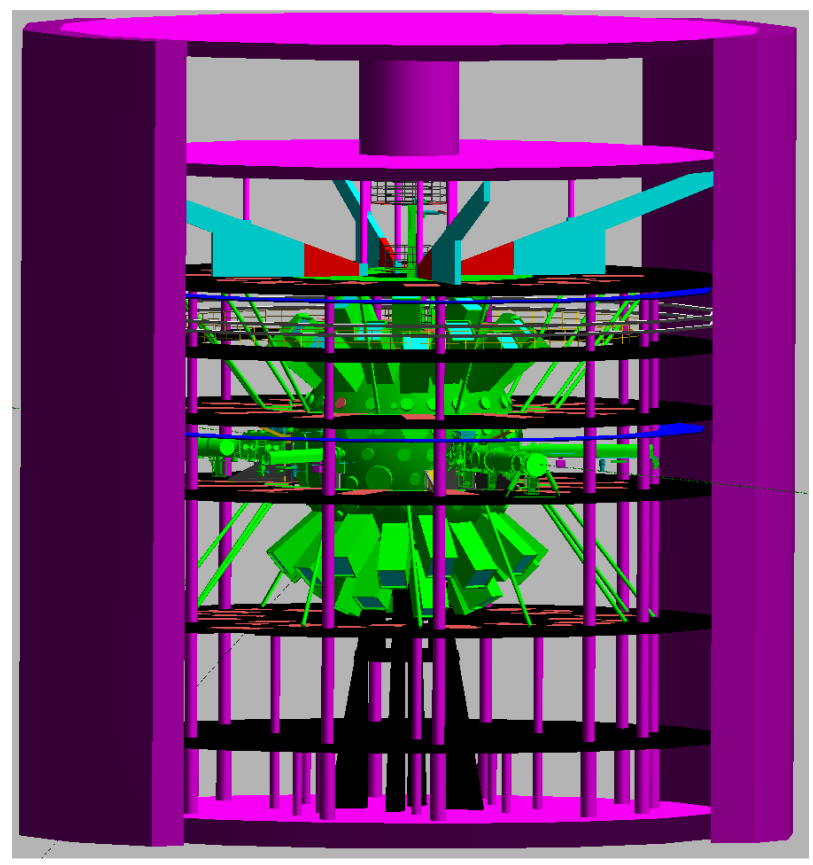

Fig. 1. Three Dimensional View of the MCNP TB Model

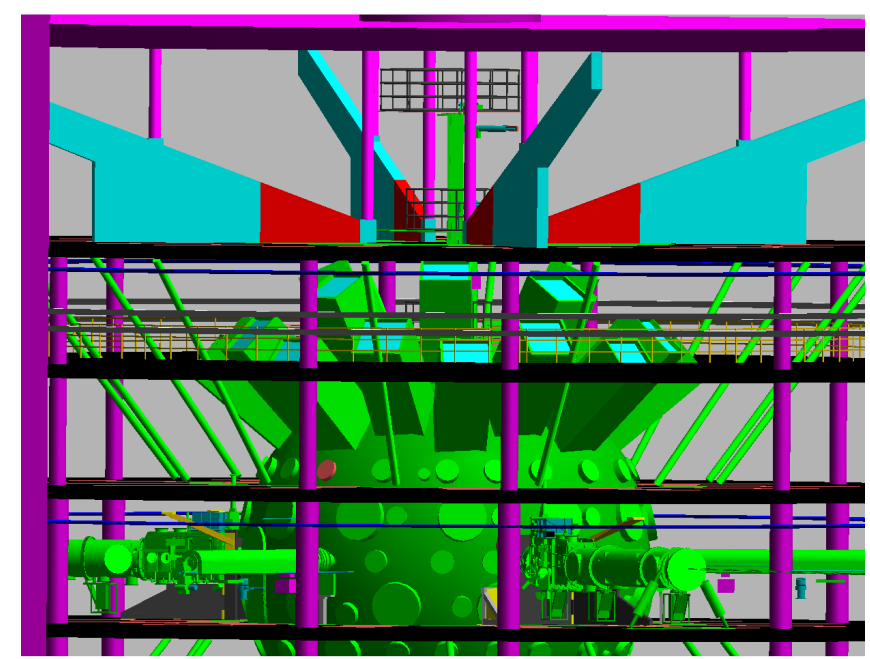

Fig. 2. MCNP Model of TB at the Equatorial region of the Target Chamber

\section{TARGET BAY MODEL}

The TB model used for radiation transport calculations with MCNP was developed based on as-built drawings and material specifications. Models for target positioners and diagnostics equipment were built with attention to detail. However, in some instances simplifying approximations were made to a specific part of the diagnostics model mainly to enhance the efficiency of the calculation. In these cases the total mass was preserved. For example, small components adjacent to each other and made of the same material were combined into one volume, thus enabling better convergence of neutron fluxes and better sampling of the gamma source.

\section{III.A. Structural Components in the Model}

The Target Chamber (TC) was modeled as concentric spheres with the first wall, chamber wall and gunite shield. The stainless steel first wall assembly was modeled with appropriate densities to preserve the total mass of the wall. The first wall assembly is $0.37 \mathrm{~m}$ thick, followed by the $0.1 \mathrm{~m}$ thick aluminum (A15083) chamber wall, which in turn is followed by $0.4 \mathrm{~m}$ of gunite shield with $1 \%$ volume steel rebar. The outer radius of the TC is $5.5 \mathrm{~m}$. Included in the model are the outer wall of the TB that has an inner radius of $15.24 \mathrm{~m}$. The concrete TB wall is $1.83 \mathrm{~m}(6 \mathrm{ft})$ thick. The various floors, support columns, support braces, some utility pipes, guard railing, maintenance platforms, and the bottom TC pedestal were modeled using as built drawings and materials. Aluminum port covers and the top plate of the TC were modeled with appropriate thicknesses and radial dimensions.

\section{III.B. Final Optic Assemblies (FOAs)}

The FOAs in the present TB model are simplified versions of a more accurate model that preserve the total mass of the aluminum structural components as well as the different optics. The aluminum structural components are the dominant contributors to the dose rate in the vicinity $(\sim 30 \mathrm{~cm})$ of an FOA. All 48 FOAs are included in the model (see Figures 1 and 2). Earlier studies on more detailed models of the FOAs ${ }^{8,9}$ determined that most of contribution to dose rate comes from the structural components of these units while the optical components do not contribute significantly to the general dose environment following the prescribed stay-out times.

\section{III.C. Target Positioners}

The cryogenic Target Positioner (CryoTARPOS) and the target positioner (TARPOS) are modeled in great details. These models exist in two forms: extended into the TC during the shot, the model used for the neutron flux spectrum calculation, and retracted following the 
shot, the model used for the gamma dose rate calculation. Figure 3 shows the MCNP model of the CryoTARPOS.

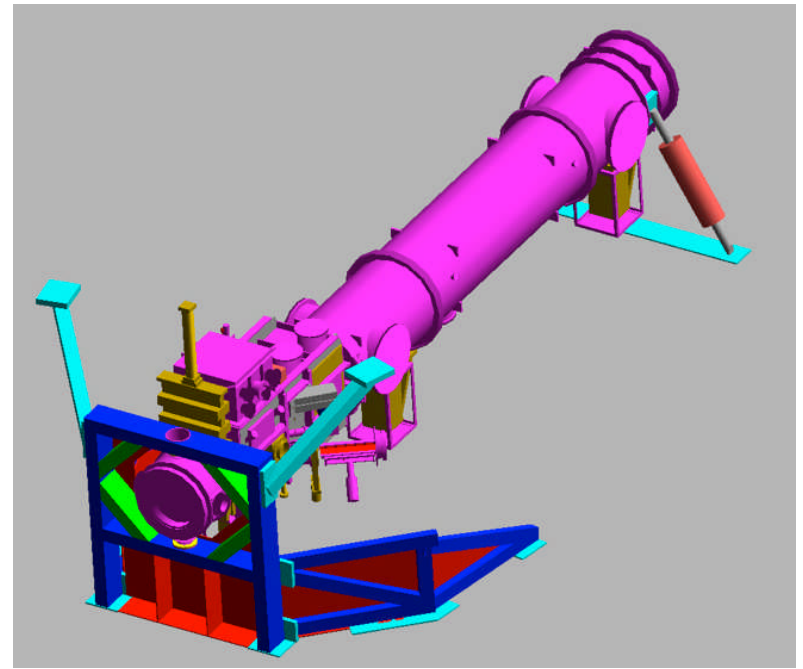

Fig. 3. MCNP Model of the CryoTARPOS

In addition to the TARPOS models, the TASPOS (Target Alignment Sensor Positioner) that aligns the lasers with the target is also included in the model. This component is always modeled in the retracted position. The target hohlraum is also included in the model.

\section{III.D. Diagnostic Instrument Manipulator}

The model includes the polar DIM located in the north pole of the TC as well as the two horizontal DIMs in the equatorial plane of the TC. These three components are also modeled with their snouts extended into the TC for the neutron spectra calculations and in the retracted mode for the gamma dose rate estimation. Figure 4 shows the MCNP model of a DIM

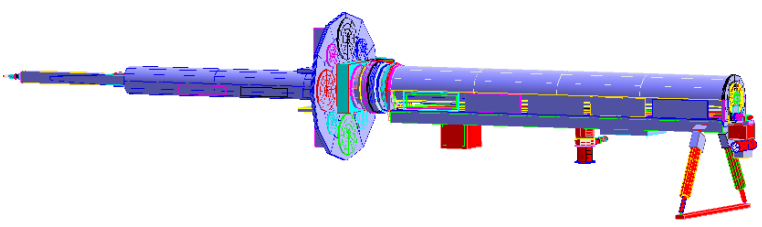

Fig. 4. MCNP Model of a DIM

\section{III.E. X-Ray Diagnostic Instruments}

The TB model includes some of the diagnostic instruments that detect x-rays from a shot. Specifically, Dante (soft x-ray diagnostic instrument for hohlraum temperature estimation), and FFLEX (Filter Fluorescer), are included in the model. Figure 5 shows the MCNP model of the Dante.

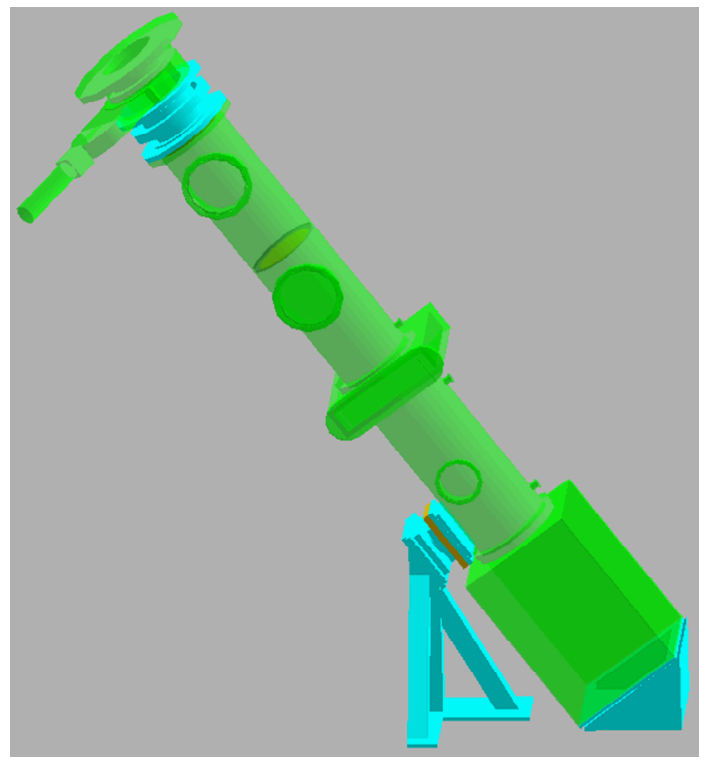

Fig. 5. MCNP Model of the Dante

\section{III.F. Magnetic Recoil Spectrometer}

The Magnetic Recoil Spectrometer (MRS) is used for high resolution neutron spectrometry. A detailed model of this diagnostic instrument is included in the TB model. Figure 6 shows the MCNP model of the MRS.

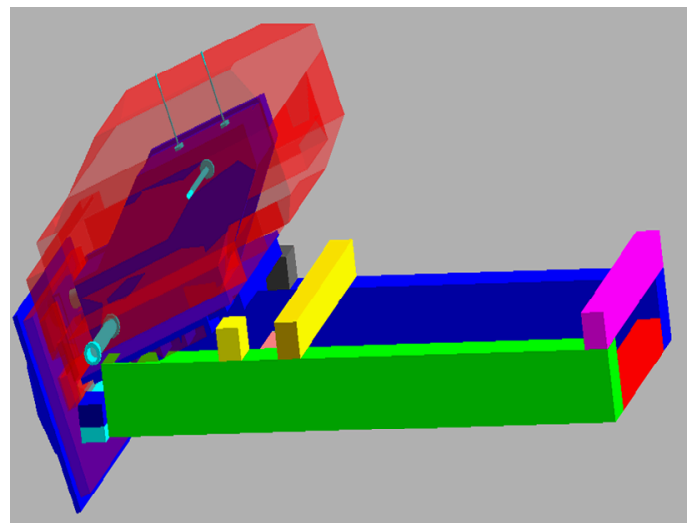

Fig. 6. MCNP Model of the MRS

\section{RESULTS}

The MCNP runs were performed typically using 4096 CPUs with clock times of approximately 24 hours per CPU. Dose maps were generated using NEET at different cooling times following a single D-T shot with a 
yield of $10^{16}$ neutrons. All dose rate values presented are for a single shot. NEET can use this data for a sequence of shots of different yields and produce dose maps including the cumulative effect of these multiple shots.

The regions of high dose rates after the shot are typically found in the vicinity $(\sim 30 \mathrm{~cm})$ of components that have parts that were withdrawn from the inside the TC following a shot. Figure 7 shows a close-up view of the CryoTarpos and the three DIMs inside the target chamber as modeled in MCNP.

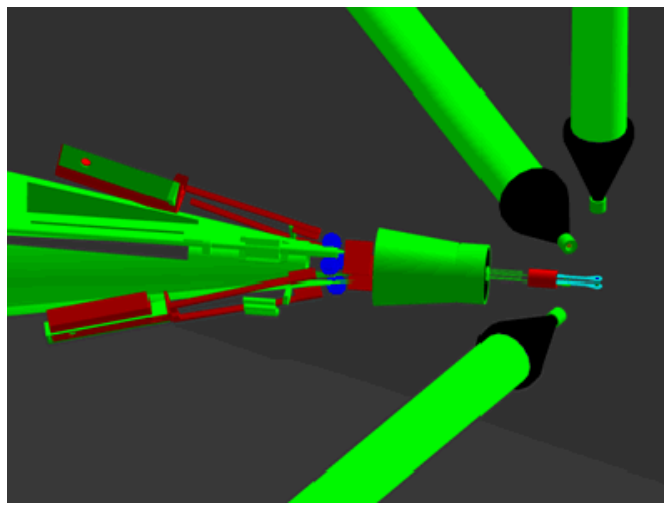

Fig. 7. Close-up View of the CryoTARPOS and the three DIMs.

Dose rates at various cooling times in the vicinity $(\sim 30 \mathrm{~cm})$ of the two equatorial DIMs are presented in Table I. The dose rates in the vicinity $(\sim 30 \mathrm{~cm})$ of the two target positioners are presented in Table II.

TABLE I. Dose Rates in the Vicinity $(\sim 30 \mathrm{~cm})$ of the Equatorial DIMs

\begin{tabular}{|l|l|l|}
\hline \multirow{2}{*}{ Cooling Times } & \multicolumn{2}{|l|}{ Dose Rates $(\mathrm{mrem} / \mathrm{h})$} \\
\cline { 2 - 3 } & DIM $(90,79)$ & DIM $(90,315)$ \\
\hline $1 \mathrm{~h}$ & 3.1 & 2.9 \\
\hline $3 \mathrm{~h}$ & 2.3 & 2.1 \\
\hline $6 \mathrm{~h}$ & 1.8 & 1.6 \\
\hline $12 \mathrm{~h}$ & 1.3 & 1.1 \\
\hline $1 \mathrm{~d}$ & 0.7 & 0.6 \\
\hline $3 \mathrm{~d}$ & 0.1 & 0.1 \\
\hline $6 \mathrm{~d}$ & $<0.1$ & $<0.1$ \\
\hline
\end{tabular}

The dose rate level 1 hour after the shot in the vicinity $(\sim 30 \mathrm{~cm})$ of the most activated regions in each of the four components on the floor that represents the equatorial region of the TC is approximately $3 \mathrm{mrem} / \mathrm{h}$ and drops to about $1 \mathrm{mrem} / \mathrm{h}$ after 12 hours. Figure 8 shows a dose rate map on the equatorial plane of the TC at $3 \mathrm{~h}$ following the shot. The hot spots inside the individual retracted components have higher contact dose rates of $\sim 20-50 \mathrm{mrem} / \mathrm{h}$ while that inside of the chamber is in the range of 7-8 $\mathrm{mrem} / \mathrm{h}$.
TABLE II. Dose Rates in the Vicinity $(\sim 30 \mathrm{~cm})$ of the two Target Positioners

\begin{tabular}{|l|l|l|}
\hline \multirow{2}{*}{ Cooling Times } & \multicolumn{2}{|l|}{ Dose Rates (mrem/h) } \\
\cline { 2 - 3 } & CryoTARPOS & TARPOS \\
\hline $1 \mathrm{~h}$ & 2.8 & 2.6 \\
\hline $3 \mathrm{~h}$ & 1.9 & 1.9 \\
\hline $6 \mathrm{~h}$ & 1.3 & 1.3 \\
\hline $12 \mathrm{~h}$ & 0.8 & 0.8 \\
\hline $1 \mathrm{~d}$ & 0.4 & 0.5 \\
\hline $3 \mathrm{~d}$ & 0.1 & 0.1 \\
\hline $6 \mathrm{~d}$ & $<0.1$ & $<0.1$ \\
\hline
\end{tabular}

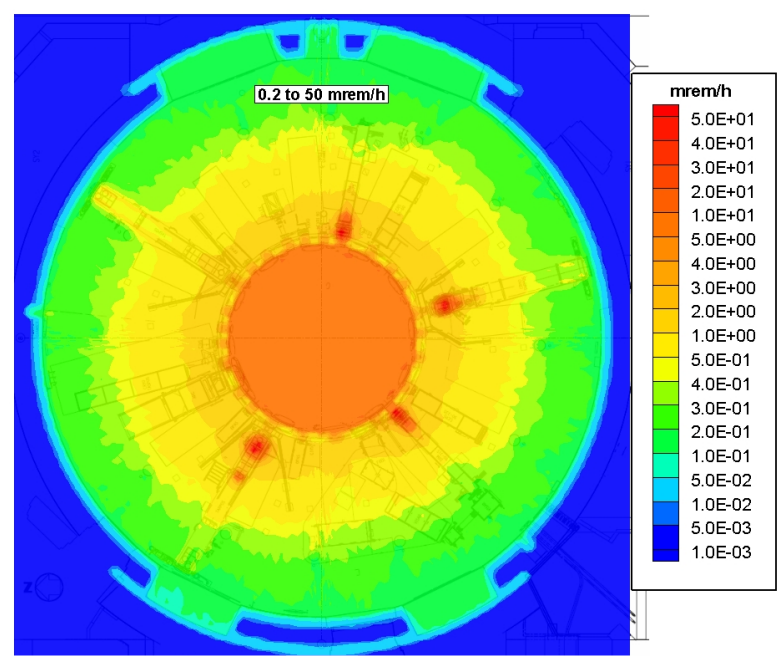

Fig. 8. Dose Rate Map at the Equatorial Plane of the TC at $3 \mathrm{~h}$ following a shot.

Dose rates at the $12.2 \mathrm{~m} \mathrm{(40} \mathrm{ft)} \mathrm{elevation} \mathrm{are} \mathrm{of}$ interest since this represents a TB floor where on occasion visitors could be present. Table III shows the dose rates at different cooling times for the north pole region of the TC

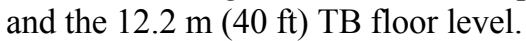

TABLE III. Dose Rates in the Vicinity $(\sim 30 \mathrm{~cm})$ of the Polar DIM and the Mezzanine Level at $12.2 \mathrm{~m}$.

\begin{tabular}{|l|l|l|}
\hline \multirow{2}{*}{ Cooling Times } & \multicolumn{2}{|l|}{ Dose Rates (mrem/h) } \\
\cline { 2 - 3 } & Polar DIM & $40 \mathrm{ft} \mathrm{TB}$ floor \\
\hline $1 \mathrm{~h}$ & 3.8 & 0.5 \\
\hline $3 \mathrm{~h}$ & 2.7 & 0.3 \\
\hline $6 \mathrm{~h}$ & 2.3 & 0.2 \\
\hline $12 \mathrm{~h}$ & 1.7 & 0.1 \\
\hline $1 \mathrm{~d}$ & 0.9 & $<0.1$ \\
\hline $3 \mathrm{~d}$ & 0.1 & $<0.1$ \\
\hline $6 \mathrm{~d}$ & $<0.1$ & $<0.1$ \\
\hline
\end{tabular}

Figure 9 shows dose rate map at the $12.8 \mathrm{~m}(42 \mathrm{ft})$ elevation near the tip of the retracted snout of the polar DIM. A hot spot of $\sim 200 \mathrm{mrem} / \mathrm{h}$ occurs inside the DIM snout with the dose rate rapidly dropping off as the distance from the DIM snout increases. 


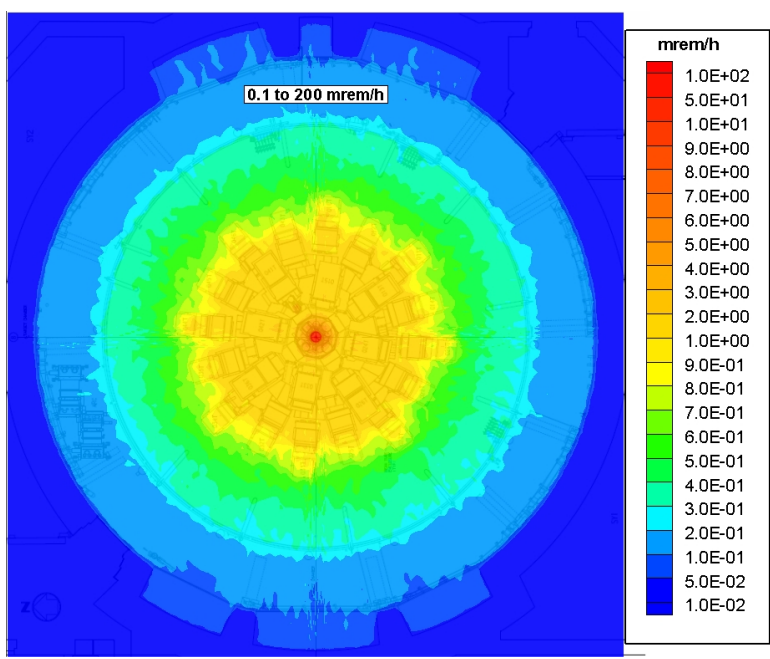

Fig. 9. Dose Rate Map at the $12.8 \mathrm{~m}$ elevation near the polar DIM at $3 \mathrm{~h}$ following a shot.

The main contributions to dose come from the activation of the various types of aluminum and steel components present in the TB. In the short term following a shot, the main contributions to the dose rate come from ${ }^{28} \mathrm{Al}\left(\mathrm{T}_{1 / 2}=2.2 \mathrm{~m} ;\langle\gamma>=1.78 \mathrm{MeV}),{ }^{27} \mathrm{Mg}\left(\mathrm{T}_{1 / 2}=9.5 \mathrm{~m}\right.\right.$; $\langle\gamma\rangle=0.9 \mathrm{MeV},{ }^{56} \mathrm{Mn}\left(\mathrm{T}_{1 / 2}=2.6 \mathrm{~h} ;\langle\gamma\rangle=1.7 \mathrm{MeV}\right)$, and ${ }^{24} \mathrm{Na}\left(\mathrm{T}_{1 / 2}=14.7 \mathrm{~h} ;\langle\gamma\rangle=4.1 \mathrm{MeV}\right) .{ }^{28} \mathrm{Al},{ }^{27} \mathrm{Mg}$, and ${ }^{56} \mathrm{Mn}$ are produced via $(\mathrm{n}, \gamma)$ reactions in ${ }^{27} \mathrm{Al},{ }^{26} \mathrm{Mg}$, and ${ }^{55} \mathrm{Mn}$, respectively. The ${ }^{24} \mathrm{Na}$ is produced via the $(\mathrm{n}, \alpha)$ reaction in ${ }^{27} \mathrm{Al}$. In the longer term, there is a dose rate component from ${ }^{24} \mathrm{Na}$ in addition to contributions from ${ }^{58} \mathrm{Co}\left(\mathrm{T}_{1 / 2}=\right.$ $70.9 \mathrm{~d} ;\langle\gamma\rangle=0.8 \mathrm{MeV})$ and ${ }^{54} \mathrm{Mn}\left(\mathrm{T}_{1 / 2}=312.2 \mathrm{~d} ;\langle\gamma\rangle=0.8\right.$ $\mathrm{MeV})$. The ${ }^{58} \mathrm{Co}$ is produced via both the (n, $2 \mathrm{n}$ ) reaction in ${ }^{59} \mathrm{Co}$ and the $(\mathrm{n}, \mathrm{p})$ reaction in ${ }^{58} \mathrm{Ni} .{ }^{54} \mathrm{Mn}$ is produced via the $(n, p)$ reaction in ${ }^{54} \mathrm{Fe}$.

\section{CONCLUSIONS}

The post-shot radiation environment inside the TB of the NIF has been characterized. Following a low-yield D$\mathrm{T}$ shot, the general environment dose rate at the equatorial region of the TC drops to $<3 \mathrm{mrem} / \mathrm{h}$ at $3 \mathrm{~h}$ after a $10^{16}$ shot. Based on the dose rate estimates evaluated in this study, general access on several floors in the TB could be allowed within an hour, but specific tasks that require accessing locations with locally higher dose rates may benefit from additional decay time to allow dose rates to drop further.

The results presented in the paper are based on the maximum yield expected in the Phase III operations of NIF and could be scaled down within the range of expected D-T neutron yields. The tool, NEET, used for work planning uses this approach to scale dose rates for successive shots to estimate cumulative dose rates at any given time after a sequence of shots.
Additional components are being added to the MCNP Target Bay model as the individual component models are developed. The goal is to capture all the large components that exist inside the TB such that the calculational model will be able to provide reasonable estimates of environmental radiation levels to populate the database that NEET uses. The future calculations will be made with shots of $20 \mathrm{MJ}$ yield, giving rise to a pulse of $7.1 \times 10^{18}$ neutrons. As measured data become available, this database will be adjusted to reconcile the calculated numbers with the measurements in order for NEET to be able to produce values that reflect actual conditions inside the Target Bay. Thus, work planning can be performed to aid in maintaining ALARA goals for NIF personnel.

\section{ACKNOWLEDGMENTS}

This work was performed under the auspices of the U.S. Department of Energy by Lawrence Livermore National Laboratory under Contract DE-AC52-07NA27344.

\section{REFERENCES}

1. X-5 Monte Carlo Team, "MCNP- A General Monte Carlo N-Particle Transport Code, Version 5," Los Alamos National Laboratory, LA-UR-031987(2005).

2. Fusion Evaluated Nuclear Data Library, FENDL-2.1, IAEA, November 2004.

3. P.P.H WILSON, D.L. HENDERSON, "ALARA: Analytic and Laplacian Adaptive Radioactivity Analysis," UWFDM-1070/1071, University of Wisconsin Fusion Technology Institute, Madison, WI (1998).

4. Evaluated Nuclear Data File, ENDF/B-VI, Release 8, National Nuclear Data Center, 2002.

5. International Commission on Radiological Protection "ICRP Publication 74: Conversion Coefficients for use in Radiological Protection against External Radiation," Pergamon Press (1997).

6. M. YOUNG, J. VERBEKE, "AAMI: Automated ALARA-MCNP Interface User's Manual," LLNLPRES-426583, Lawrence Livermore National Laboratory (2010).

7. NEET: NIF Exposure Estimation Tool, NIF0116620, Lawrence Livermore National Laboratory, June 2010.

8. L.S. DAUFFY, H.Y. KHATER, S. SITARAMAN, S. BRERETON, "Activation Analysis of the Final Optics Assemblies at the National Ignition Facility", Fusion Science and Technology 56 (2) 736 (2009).

9. S. SITARAMAN, H. KHATER, L. DAUFFY, S. BRERETON, "Neutron Activation of NIF Final Optics Assemblies", Journal of Physics: Conference Series, Volume 244 (2010), 032025. 